\title{
Evaluasi Workshop Perancangan Video Pembelajaran Interaktif sebagai Penunjang Kompetensi Tenaga Pendidik
}

\author{
Luthfiana Tarida ${ }^{1,2}$ \\ ${ }^{1}$ Akademi Maritim Nusantara Cilacap \\ ${ }^{2}$ Universitas Negeri Surabaya \\ luthfianatarida@amn.ac.id, luthfiana.21012@mhs.unesa.ac.id
}

Diterima 11 September 2021, direvisi 24 September, diterbitkan 06 Oktober 2021

\begin{abstract}
Abstrak
Kompetesi tenaga pendidik dalam merancang media pembelajaran sangat diperlukan terutama dalam menghadapi tantangan perubahan paradigma pendidikan era pandemi Covid-19. Perubahan ini mengarah kepada pembelajaran online untuk menekan angka penyebaran Covid-19. Video merupakan media interaktif yang digunakan pada saat pembelajaran online. Namun, tidak semua tenaga pendidik dibekali kompetensi dalam merancang video pembelajaran interaktif. Workshop perlu dilakukan untuk menunjang kompetensi tenaga pendidik. Evaluasi workshop juga perlu dilakukan agar dapat menganalisis kekurangan dan kelebihan selama pelaksanaan, sehingga dapat dijadikan dasar perbaikan untuk workshop selanjutnya. Tujuan dari penelitian ini yaitu menganalisis evaluasi workshop tersebut. Evaluasi yang dilakukan merupakan evaluasi proses selama pelaksanaan kegiatan. Teknik analisis data yang digunakan yaitu statistik deskriptif. Instrumen pengumpul data yang digunakan yaitu kuisioner dengan skala likert. Data dianalisis dengan menghitung rerata skor setiap butir pernyataan kemudian disimpulkan secara deskriptif. Hasil penelitian menginformasikan bahwa kegiatan workshop dilaksanakan dalam 3 tahapan yaitu pemilihan materi yang mendukung kegiatan interaktif, pengambilan video sesuai dengan materi, serta pengeditan video dan materi menggunakan aplikasi kinemaster. Kesimpulan evaluasi dari workshop yaitu, kegiatan sudah dilaksanakan dengan baik, namun ada beberapa kekurangan seperti alokasi waktu yang terlalu sedikit. Kekurangan tersebut dapat dijadikan bahan perbaikan untuk kegiatan workshop selanjutnya sehingga kompetensi guru dapat dimaksimalkan.Misalnya, merancang susunan acara dengan alokasi waktu yanng tepat dan atau menambah jumlah fasilitator berdasarkan jumlah peserta kegiatan.
\end{abstract}

Kata kunci : Evaluasi, Workshop, Video

\begin{abstract}
The competition of educators in designing learning media is needed especially in facing the challenges of changing the educational paradigm of the Covid-19 pandemic era. This change leads to online learning to reduce the number of Covid-19 spread. Video is one of the interactive media that can be used during online learning. However, not all educators are equipped with competence in designing interactive learning videos. Workshops need to be done to support the competence of educators. Workshop evaluation also needs to be done in order to analyze the shortcomings and advantages during the implementation, so that it can be used as a basis for improvement for the next workshop. Therefore, this study aims to analyze the evaluation of the workshop. Evaluation is an evaluation of the process during the implementation of activities. This research is quantitative research with descriptive statistical data analysis techniques. The data collection instrument used is a questionnaire with a likert scale. The data is analyzed by calculating the average score of each statement item and then concluded descriptively. The results of the study inform that the workshop activities are carried out in 3 stages, namely the selection of materials that support interactive activities, video capture in accordance with the material, and video editing and materials using kinemaster applications. The conclusion of the evaluation of the workshop is that the activities have been carried out well, but there are some shortcomings such as the allocation of too little time. These shortcomings can be used as improvement materials for further workshop activities so that teacher competence can be maximized. For example, designing the arrangement of events with the right time allocation and or increasing the number of facilitators based on the number of activity participants.
\end{abstract}




\section{Pendahuluan}

Kompetensi guru perlu ditingkatkan terutama dalam menghadapi era pandemi Covid-19 yang membawa perubahan paradigma pendidikan secara massive dan mendadak. Kompetensi guru yang meningkat tentunya akan berdampak pada pendidikan yang berkualitas. Hal ini sejalan dengan UU No 20 Tahun 2003, yang menyatakan "setiap warga negara berhak memperoleh pendidikan yang bermutu".

Peningkatan kualitas pembelajaran, dapat didukung dengan penggunaan teknologi informasi, sesuai dengan revolusi industri 4.0. Pembelajaran era pandemi Covid-19, juga membutuhkan pemanfaatan teknologi informasi yang tepat guna. Pembelajaran dari jenjang SD hingga Perguruan Tinggi dilakukan secara online guna meminimalisir kontak fisik sehingga mampu menekan angka kenaikan pasien Covid19. Pembelajaran online yang berkualiatas tentu membutuhkan bantuan teknologi. Kualitas pembelajaran dapat ditingkatkan melalui peran guru, siswa, sistem/sekolah, lingkungan dan bahan ajar/fasilitas. Kemampuan guru beradaptasi dan berinovasi dengan kemajuan teknologi mendorong antusias siswa dalam belajar [1].

Hasil wawancara pada beberapa guru SMP di Kabupaten Cilacap, menginformasikan siswa kesulitan memahami materi saat pembelajaran jarak jauh di era pandemi Covid-19. Materi yang dianggap sulit adalah matematika. Siswa merasa kesulitan dalam memahami konsep matematika, padahal pemahaman konsep matematika merupakan hal mendasar yang harus dimiliki siswa dalam proses belajar matematika [2].

Video pembelajaran matematika dapat dijadikan solusi alternatif dalam meningkatkan pemahaman konsep siswa. Hal ini didukung hasil penelitian-penelitian sebelumnya. Penerapkan media video youtube dalam pembelajaran dapat menghadirkan sesuatu yang dapat dilihat dan didengar sehingga dapat memotivasi siswa dan memberikan pengalaman belajar [3]. Hasil penelitian sebelumnya menyatakkan bahwa peningkatan pemahaman konsep matematika siswa SMP meningkat dengan video animasi matematika [2]. Penelitian lain juga memberikan hasil yang positif tentang penggunaan video pembelajaran [3]. Pemahaman konsep siswa yang menggunakan media video lebih unggul dibandingkan kelas yang tidak menggunakan media video. Penelitian oleh Afifah menyatakkan perhatian siswa dapat terfokus dengan penggunaan video dalam pembelajaran sehingga dapat meningkatkan hasil belajarnya [3].

Hasil penelitian-penelitian sebelumnya tersebut, menjadi alasan kuat untuk mengadakan pelatihan pembuatan video pembelajaran bagi guru. Berdasarkan wawancara, ditemukan kendala terdapat beberapa guru-guru yang belum menggunakan video pembelajaran karena keterbatasan kompetensi dalam membuat video tersebut. Melalui workshop pembuatan video, diharapkan dapat meningkatkan kompetensi guru sehingga memberikan pengaruh positif pada pemahaman konsep matematika siswa. Hal ini karena salah satu cara membantu guru dalam meningkatkan kualitas pembelajaran yaitu dengan menyiapkan program pengembangan profesi guru [4]. Pada penelitian ini, akan dianalisis lebih jauh mengenai evaluasi workshop perancangan video pembelajaran interaktif sebagai penunjang komptensi tenaga pendidik.

\section{Materi dan Metode}

Workshop merupakan kegiatan pelatihan yang dilaksanakan dengan tujuan tertentu. Video merupakan suatu perangkat yang berfungsi sebagai penerima gambar dan suara [5]. Dengan digunakannya video sebagai media pembelajaran, diharapkan lebih memfasilitasi kemampuan berpikir siswa, karena siswa tidak hanya melihat gambar ataupun mendengarkan suara, tetapi dapat memahami makna dari gabungan dua unsur tersebut. Evaluasi yang dilakukan pada penelitian ini merupakan monitoring yang berkaitan dengan peran workshop video pembelajaran interaktif dalam menunjang kompetensi tenaga pendidik yang diharapkan. Hasil dari evaluasi proses dapat dijadikan umpan balik untuk ditindaklanjuti [6]. Dengan adanya evaluasi diharapkan dapat dijadikan acuan perbaikan apabila terdapat kekurangan selama proses pelatihan/workshop, sehingga dapat lebih meningkatkan kompetensi guru dalam merancang video pembelajaran interaktif.

Pendekatan yang digunakan dalam mengolah data penelitian ini yaitu penelitian kuantitatif. 
Data dianalisis menggunakan statistik deskriptif [7]. Subjek dalam penelitian ini yaitu guru di SMP Negeri 06 Cilacap. Instrumen yang digunakan berupa kuisioner dengan skala likert, yang dibagikan pada akhir kegiatan workshop. Hasil pengisian kuisioner diolah dengan statistik secara deskriptif sehingga didapat data mengenai rerata evaluasi kegiatan workshop. Data juga disajikan dalam tabel dan diagram untuk disimpulkan secara deskriptif tentang evaluasi proses pelaksanaan workshop perancangan video pembelajaran interaktif sebagai penunjang kompetensi tenaga pendididik.

\section{Hasil dan Pembahasan}

Kegiatan workshop difasilitasi dengan modul dan video tutorial. Kegiatan workshop dilaksankakan dalam tiga tahapan yaitu pemilihan materi, pembuatan/take video sesuai dengan materi, dan mengedit video serta materi menggunakan aplikasi kinemaster.

Deskripsi data dapat dilihat pada Tabel 1 berikut.

Tabel 1. Data Hasil Kuisioner

\begin{tabular}{|c|c|c|c|}
\hline No & Butir Pernyataan & $\begin{array}{l}\text { Rerata } \\
\text { Skor }\end{array}$ & Kategori \\
\hline 1 & $\begin{array}{l}\text { Materi terorganisasi } \\
\text { dengan baik dan mudah } \\
\text { dimengerti }\end{array}$ & 3,875 & Baik \\
\hline 2 & $\begin{array}{l}\text { Materi sangat relevan } \\
\text { dan telah sesuai dengan } \\
\text { yang saya harapkan }\end{array}$ & 4,000 & Baik \\
\hline 3 & $\begin{array}{lr}\text { Materi } & \text { sudah } \\
\text { mencukupi } & \text { bagi saya } \\
\text { untuk } & \text { mampu } \\
\text { menyusun } & \text { video } \\
\text { pembelajaran interaktif }\end{array}$ & 3,250 & Sedang \\
\hline 4 & $\begin{array}{l}\text { Pemateri sangat } \\
\text { memahami materi yang } \\
\text { dipresentasikan }\end{array}$ & 3,750 & Baik \\
\hline 5 & $\begin{array}{ll}\begin{array}{ll}\text { Alokasi } \\
\text { penyampaian } \\
\text { mencukupi }\end{array} & \text { materi } \\
\end{array}$ & 3,125 & Sedang \\
\hline 6 & $\begin{array}{l}\text { Pemateri } \\
\text { mempresentasikan isi } \\
\text { materi dengan baik; } \\
\text { mudah dimengerti dan } \\
\text { diimplementasikan }\end{array}$ & 3,875 & Baik \\
\hline 7 & $\begin{array}{l}\text { Alokasi waktu untuk } \\
\text { diskusi mencukupi } \\
\text { untuk menambah/ } \\
\text { memperkuat } \\
\text { pemahaman saya }\end{array}$ & 3,250 & Sedang \\
\hline 8 & $\begin{array}{lr}\text { Pemateri } & \text { memberikan } \\
\text { jawaban } & \text { terhadap } \\
\text { pertanyaan } & \text { peserta } \\
\end{array}$ & 4,000 & Baik \\
\hline
\end{tabular}

\begin{tabular}{|c|c|c|c|}
\hline No & Butir Pernyataan & $\begin{array}{c}\text { Rerata } \\
\text { Skor }\end{array}$ & Kategori \\
\hline & dengan baik & & \\
\hline 9 & $\begin{array}{l}\text { Secara keseluruhan } \\
\text { diskusi/tanya-jawab } \\
\text { telah sangat membantu } \\
\text { meningkatkan } \\
\text { pemahaman peserta }\end{array}$ & 3,875 & Baik \\
\hline 10 & $\begin{array}{lr}\text { Panduan } & \text { praktik } \\
\text { perancangan } & \text { video } \\
\text { pembelajaran } & \text { telah } \\
\text { disediakan dengan baik. }\end{array}$ & 3,750 & Baik \\
\hline 11 & $\begin{array}{l}\text { Panduan } r \text { disusun } \\
\text { dengan baik dan mudah } \\
\text { dimengerti }\end{array}$ & 3,750 & Baik \\
\hline 12 & $\begin{array}{l}\text { Dengan panduan dan } \\
\text { waktu yang disediakan } \\
\text { serta bantuan fasilitator } \\
\text { maka praktik dapat } \\
\text { berjalan dengan baik }\end{array}$ & 3,750 & Baik \\
\hline & Total & 3,6875 & Baik \\
\hline
\end{tabular}

Berdasarkan Tabel 1, diperoleh informasi secara deskriptif bahwa rerata skor evaluasi yang diberikan guru terhadap wokrshop yang diikuti yaitu 3,6875. Rerata tersebut jika dibulatkan menjadi skor 4 yang memiliki arti setuju terhadap butir pernyataan yang diberikan. Secara deskriptif dapat disimpulkan bahwa workshop perancangan video pembelajaran interaktif dapat menunjang kompetensi tenaga pendidik.

Skor terendah terdapat pada butir pernyataan nomor 5, yaitu terkait alokasi waktu penyampaian materi, dengan skor 3,125. Skor tertinggi terdapat pada dua butir pernyataan, yaitu (1) materi sangat relevan dan telah sesuai dengan yang saya harapkan, dan (2) pemateri memberikan jawaban terhadap pertanyaan peserta dengan baik.

Rincian data dengan skor jawaban terendah dijelaskan lebih lanjut dalam bentuk diagram batang:

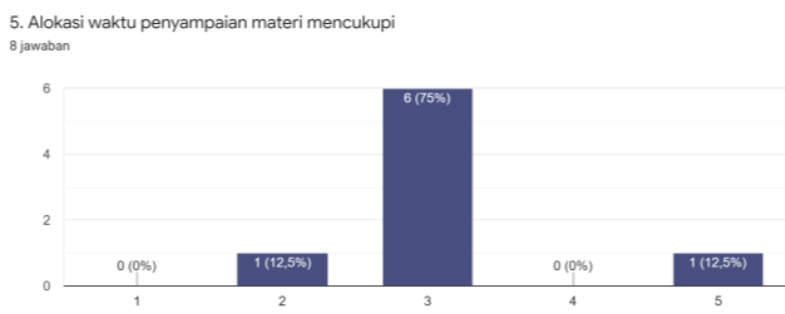

Gambar 2. Diagram Batang Presentase Jawaban Terendah

Terdapat $12,5 \%$ peserta yang memberikan skor 2, dengan artian tidak ada alokasi waktu yang baik dalam pelaksanaan workshop. Namun 
terdapat juga $12,5 \%$ peserta yang menyatakan alokasi waktu sudah cukup baik. Jawaban terbanyak memberikan skor 3, dengan presentase $75 \%$ yang memberikan penilaian sedang terhadap alokasi waktu penyampaian materi.

Diagram batang untuk skor tertinggi disajikan pada Gambar 3 dan Gambar 4 berikut.

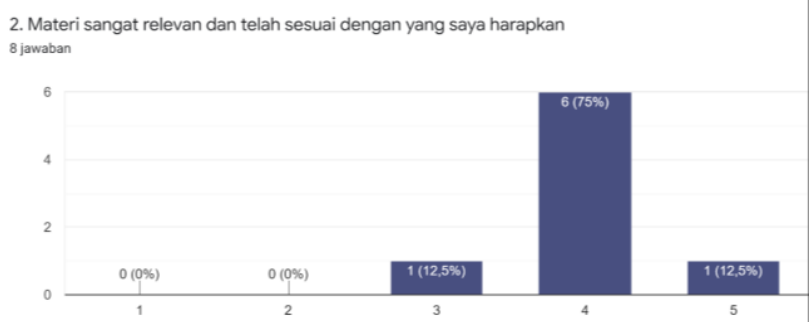

Gambar 3. Diagram Batang Presentase Jawaban Tertinggi Butir Nomor 2

Terdapat $75 \%$ peserta memberikan penilaian baik terhadap materi yang diberikan selama workshop. Menurut peserta workshop, materi perancangan video pembelajaran sangat diperlukan agar pembelajaran online dapat berjalan secara interaktif.

Skor tertinggi berikutnya ada pada butir nomor 8 yang disajikan secara rinci pada Gambar 4.

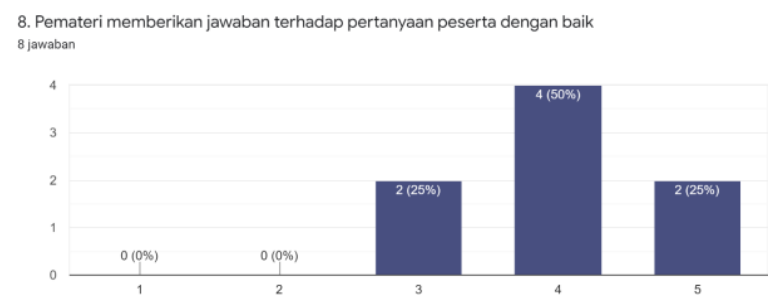

Gambar 4. Diagram Batang Presentase Jawaban Tertinggi Butir Nomor 8

Proporsi jawaban pada butir nomor 8 yaitu terdapat $25 \%$ peserta yang menjawab sedang, $50 \%$ peserta menjawab baik dan $25 \%$ menjawab sangat baik untuk pernyataan pemateri memberikan jawaban terhadap pertanyaan peserta

Berdasarkan data-data yang diperoleh, dapat kegiatan wokrshop dapat dievaluasi agar pada kegitan berikutnya berjalan dengan lebih baik. Jawaban terendah pada butir alokasi waktu, sejalan dengan beberapa saran dari guru yang menyatakan bahwa pelaksanaan kegiatan sudah cukup baik, namun perlu adanya penambahan waktu praktek pembuatan video. Alokasi waktu yang telah direncanakan ternyata kurang dapat memfasilitasi peserta workshop dengan baik. Hal ini juga dikarenakan perbandingan jumlah fasilitator yang kurang memadai terhadap jumlah peserta. Pada kesempatan workshop berikutnya, akan dirancang alokasi waktu dengan meninjau materi, susunan acara kegiatan, perbandingan jumlah fasilitator dan peserta agar tujuan dari pelatihan dapat dicapai secara maksimal.

Keberhasilan video pembelajaran sebagai media belajar interaktif, sejalan dengan hasil dari penelitian sebelumnya, yang menyatakan prestasi belajar ranah kognitif siswa kelas yang memperoleh pembelajaran menggunakan video lebih baik dibandingkan prestasi belajar siswa yang tidak menggunakan video [8]. Hal ini didukung juga oleh pernyataan Majid, bahwa kelebihan pembelajaran menggunakan video yaitu, menciptakan kemandirian belajar, komunikatif dan dapat diulang, menampilkan sesuatu dengan detail dan kompleks, dapat diulang, diperlambat, bahkan diperbesar dan membandingkan antara dua atau lebih adegan secara bersamaan [9]. Keunggulan tersebut mewakili kata interaktif, siswa dapat memperoleh pengalaman belajar yang lebih konkret, sehingga mampu meningkatkan pemahaman siswa terhadap suatu konsep, termasuk saat pembelajaran online di era pandemi Covid-19.

Secara deskriptif dapat disimpulkan bahwa, workshop sudah dilaksanakan dengan baik sehingga diharapkan dapat menunjang kompetensi guru dalam merancang video pembelajaran. Video pembelajaran merupakan media yang dapat menjadi salah satu alternatif bagi pembelajaran khusunya untuk pembelajaran online di era pandemi Covid-19. Penggunaan video interaktif pembelajaran dapat mempermudah peserta didik untuk memahami materi yang diajarkan meskipun tidak melakukan pembelajaran di dalam kelas [10].

\section{Kesimpulan}

Kegiatan workshop dilaksanakan dalam 3 tahapan yaitu pemilihan materi yang mendukung kegiatan interaktif, pengambilan video sesuai dengan materi, serta pengeditan video dan materi menggunakan aplikasi kinemaster. Kesimpulan evaluasi dari workshop yaitu, kegiatan sudah dilaksanakan dengan baik, namun ada beberapa kekurangan seperti alokasi waktu yang terlalu sedikit. Kekurangan tersebut dapat dijadikan bahan perbaikan untuk kegiatan workshop 
selanjutnya sehingga kompetensi guru dapat dimaksimalkan.

\section{Ucapan terima kasih}

Penyelesaian penelitian ini, melibatkan konstribusi dari berbagai pihak. Oleh karena itu penulis mengucapkan terimakasih kepada Akademi Maritim Nusantara, SMP Negeri 06 Cilacap, khususnya para peserta workshop perancangan video pembelajaran interaktif.

\section{Daftar Pustaka}

[1] A. Dhoruri, Sugiyono, E. Retnowati, D. Lestari, and E. R. Sari, "Pelatihan Geogebra 2D dan 3D untuk Meningkatkan Kemampuan Teknologi Informasi Guru di DIY dalam Pembelajaran Matematika," Lap. PPM Univ. Negeri Yogyakarta, 2016.

[2] F. R. Sari, "Penerapan Pembelajaran Example Non Example Berbantu Video Animasi Matematika Untuk Meningkatkan Pemahaman Konsep Siswa," EKUIVALEN - Pendidik. Mat., vol. 31, no. 1, pp. 37-42, 2018, [Online]. Available:

http://ejournal.umpwr.ac.id/index.php/ek uivalen/article/view/4351/4051.

[3] P. Istiqomah, I. K. Werdhiana, and U. Wahyono, "Pengaruh Penggunaan Media Video Terhadap Peningkatan Pemahaman Konsep Suhu dan Kalor Pada Siswa Kelas X MAN 1 Palu," J. Pendidik. Fis. Tadulako, vol. 5, no. 3, pp. 28-32, 2020.

[4] S. M. Patahuddin, S. Rokhmah, E. L. W. Palupi, and O. E. Nubatonis, "PENGARUH WORKSHOP PMRI TERHADAP PERUBAHAN PEMIKIRAN GURU TENTANG MATEMATIKA Sitti Maesuri Patahuddin , 2 Siti Rokhmah , 3 Evangelista Lus Windyana Palupi and Ofirenty Elyada Nubatonis," 2nd South East Asian Conf. Math. ITS Apl., no. November, pp. 1-8, 2010.

[5] Rasiman, A. A. Nugroho, and D. Purwosetiyono, "DIKEMAS DALAM BENTUK CD INTERAKTIF PADA MATA KULIAH INOVASI PEMBELAJARAN MATEMATIKA
Program Studi Pendidikan Matematika FPMIPA IKIP PGRI Semarang Jl . Sidodadi Timur 24 Semarang," Aksioma J. Mat. dan Pendidik. Mat., vol. 3, no. 1, pp. 1-9, 2012.

[6] H. Firman, "Monitoring and evaluation strategy of lesson study programme (strategi monitoring dan evaluasi program lesson study)," Int. Conf. Lesson Study, 2008.

[7] "Sugiyono. 2012. Metode Penelitian Pendidikan: Pendekatan Kuantitaif, Kualitatif dan R\&D. Bandung: Alfabeta," p. 2012, 2012.

[8] D. A. Prasetya, A. B. Santoso, and Sriyono, "EFEKTIVITAS MEDIA PEMBELAJARAN BERBASIS VIDEO STREAMING TERHADAP PRESTASI BELAJAR MATA PELAJARAN GEOGRAFI SISWA KELAS XI IPS SMA NEGERI 1 KENDAL TAHUN AJARAN 2013/2014," Edu Geogr., vol. 3, no. 4, pp. 1-8, 2015.

[9] E. Nurdin, A. Ma'aruf, Z. Amir, R. Risnawati, N. Noviarni, and M. P. Azmi, "Pemanfaatan video pembelajaran berbasis Geogebra untuk meningkatkan kemampuan pemahaman konsep matematis siswa SMK," J. Ris. Pendidik. Mat., vol. 6, no. 1, pp. 87-98, 2019, doi: 10.21831/jrpm.v6i1.18421.

[10] A. M. Budi and H. Siswantari, "Video Interaktif Materi Tangga Nada Sebagai Media Pembelajaran di Era Pandemi Covid-19," Musik. J. Pertunjuk. dan Pendidik. Musik, vol. 3, no. 1, pp. 52-61, 2021, doi: 10.24036/musikolastika.v3i1.58. 